\title{
JOVENS DE UM RURAL BRASILEIRO: SOCIALIZAÇÃO, EDUCAÇÃO E ASSISTÊNCIA*
}

VANDA SILVA*

\begin{abstract}
RESUMO: No momento em que as fronteiras entre o rural e o urbano diminuem cada vez mais e diferentes universos culturais se interpenetram, as dificuldades socioeconômicas dificultam a vida de quem vive da agricultura, emerge a juventude rural como uma população profundamente afetada por estes processos. População esta que, por muito tempo, passou despercebida das pesquisas acadêmicas brasileiras. Este artigo, portanto, chama a atenção para os jovens rurais, a partir de um estudo que procurou fornecer pistas para projetos que pretendam diminuir a evasão escolar e o analfabetismo em regiôes como a do Vale do Jequitinhonha - Minas Gerais.
\end{abstract}

Palavras-chave: Jovens rurais. Identidade. Educação. Socialização. Assistência

The Brazilian rural youth:

SOCIALIZATION, EDUCATION AND ASSISTANCE

ABSTRACT: As the borders between rural and urban zones tend to vanish and different cultural worlds get mixed, the socio-economic difficulties make life a hardship for whoever lives from agriculture. The rural youth emerges as a population deeply affected by these processes. For a long time, this population has not been the object of academic research in Brazil. This article is thus aimed at calling the attention to the fate of the Brazilian rural youth, based on a research that tried to give hints to projects intending to di-

\footnotetext{
* Agradeço a Elzbieta Proga pelos cuidados com a língua inglesa.

** Mestre em Educação, doutoranda em Ciências Sociais (Instituto de Filosofia e Ciências Humanas) na Universidade Estadual de Campinas (UniCAMP) e bolsista da Fundação de Amparo à Pesquisa do Estado de São Paulo (FAPESP). E-mail: vandas7@yahoo.com.br
} 
minish drop-out and illiteracy rates in such regions as the Vale do Jequitinhonha, Minas Gerais, Brazil.

Key words: Rural youth. Identity. Education. Socialization. Assistance

$E$

ste texto se baseia na experiência de pesquisa para a elaboração de uma dissertação de mestrado, ${ }^{1}$ realizada com jovens de 15 a 25 anos de idade, no município de Chapada do Norte, Vale do Jequitinhonha (MG), e que tratou da construção das identidades desses jovens, tal como elas se mostram com suas articulaçôes nos "modos de ser, de sentir e de se representar". A partir dos depoimentos e "observação participante" foi possível verificar como estes jovens atribuem sentido às suas vidas mediante os cruzamentos de expectativas e frustrações e os conflitos originados por influências culturais externas, tais como televisão, rádio, migrações etc., que comunicam outros significados.

Nessa busca de conhecer os jovens do sertão, emergiram questôes de extrema relevância e que não puderam ser esgotadas numa dissertação de mestrado, como, por exemplo, a possibilidade de se pensar em culturas juvenis no rural. ${ }^{2}$ No entanto, neste texto apresentarei experiências de jovens que participaram de um projeto educacional e um programa de assistência em Chapada do Norte, na região do Vale do Jequitinhonha, Minas Gerais. O primeiro trata-se do projeto da Secretaria de Educação do Estado de Minas Gerais Acertando o passo (um projeto voltado ao ensino fundamental) -; o segundo, do Programa de Apadrinhamento do Fundo Cristão para Crianças (um programa vinculado à Associação Chapadense de Assistência ao Trabalhador Rural e à Infância - ACHANTI).

Porém, nunca é demais sublinhar que os estudos sobre juventude vêm se configurando numa importante preocupação entre pesquisadores e profissionais de várias áreas, uma vez que apontam para questôes de âmbito sociocultural, educacional e econômico. No caso brasileiro, nos seus vários contextos, verificam-se os altos índices de evasão escolar, violência, gravidez precoce, desemprego, além da crescente vulnerabilidade às doenças infecto-contagiosas, drogas e suicídio entre os jovens.

Todavia, tratar da juventude como conceito não tem sido nada fácil, principalmente quando este se confunde ou é sinônimo da denominação-conceito de "adolescente". Como salienta Maria Rita de Assis César (1998): 
(...) as pesquisas que tomam a 'adolescência' como um 'objeto natural' assumem como ponto de partida uma idéia extemporânea, datada e localizada, demarcada por conceitos e metodologias oriundas de uma configuração específica do saber ocidental: o positivismo científico do século XIX e suas derivaçôes, tais como a medicina higienista e a eugenia. (p. 2)

A juventude, como construção social, tem sido vista como uma "fase da vida". Fase esta marcada pela instabilidade e incertezas que são relacionadas a "problemas sociais" (ver Machado Pais, 1993), freqüentemente associados aos jovens do universo urbano. Um dos desdobramentos dos assim denominados "problemas sociais" são as tensões que vão sendo gestadas em torno da vontade de permanecer por muito mais tempo longe das responsabilidades, tais como casamento e constituição de família, para dedicar-se a outros projetos (estudo, profissão, divertimentos, por exemplo) e um mercado de trabalho cada vez mais restrito aos jovens com ou sem experiência profissional.

Nesse caso, mesmo que se queira levar uma vida de hedonismo e não havendo possibilidades de serem sustentados pelos pais, os jovens terão de trabalhar. $\mathrm{Ou}$, então, frustrados com o desemprego, muitos destes render-se-ão ao mundo da criminalidade. Embora o desemprego não deva ser considerado como o único fator determinante para que os jovens entrem para o mundo do crime.

Se tais problemas são freqüentemente atribuídos aos jovens do universo urbano, o que sabemos sobre os jovens do rural brasileiro? Até bem recentemente, a juventude rural passava despercebida pelas pesquisas acadêmicas e projetos voltados para o universo rural (Carneiro, 1998). Porém, esta categoria vem se impondo aos pesquisadores como a mais afetada pelas transformaçôes que o campo vem sofrendo, oriundas de processos econômicos que deflagraram na desestabilização da agricultura familiar. Carneiro (op. cit.) diz que,

(...) a juventude rural salta aos olhos como a faixa demográfica que é afetada de maneira mais dramática por essa dinâmica de diluição das fronteiras entre os espaços rurais e urbanos, combinada com o agravamento da situação de falta de perspectivas para os que vivem da agricultura. (p. 97)

Se a juventude rural brasileira era ou ainda é pouco pesquisada, quando surgem pesquisas, estas "referem-se ao jovem apenas na condição de aprendiz de agricultor no interior dos processos de socialização e de divisão social do trabalho no seio da unidade familiar, o que os tornam adultos precoces já que passam a ser enxergados uni- 
camente pela ótica do trabalho" (idem, ibid.). Deste modo, nas minhas andanças pela região do Vale do Jequitinhonha, tenho carregado comigo as seguintes perguntas: Quem são esses jovens? Como vivem? O que desejam? Sendo que tais indagações ainda continuam presentes no plano de minhas sondagens sobre os jovens rurais, principalmente os de Chapada do Norte.

Jovens estes que, também, não seriam percebidos caso fossem incorporados a uma abordagem sobre a "divisão social do trabalho no seio da unidade familiar" ou mesmo como aprendizes de agricultor, pois seriam diluídos num processo sociocultural e econômico mais amplo. É fato que na regiaao e no município pesquisado, o que "salta aos olhos" é o processo da migração sazonal para o mercado da agroindústria nos municípios paulistas e do sul mineiro. Assim sendo, muitos jovens também aparecem como migrantes sazonais, sendo que poderiam ser vistos como um grupo homogêneo com práticas, comportamentos e interesses afins. Porém, nem todos os jovens de Chapada do Norte e demais municípios do Vale do Jequitinhonha são trabalhadores migrantes e, tampouco, em sendo migrantes, pensam ou agem de modo semelhante.

Desse modo, este texto alude justamente sobre as dificuldades de rapazes e moças com relação a educação formal, entrecruzando a educação informal (familiar, rede de parentela, ${ }^{3}$ grupo de teatro) e a não-formal (outros aprendizados, treinamentos através da associação local, ACHANTI). Dificuldades estas, muitas vezes, originadas pelas necessidades de luta pela subsistência. Entretanto, chamo a atenção para o fato de que, nesse município do Vale do Jequitinhonha, encontrei jovens que estão fazendo faculdade em outras cidades mineiras. Jovens que estão desempregados e fora da escola; que estudam e trabalham no rural; que moram em repúblicas na área urbana do referido município para poderem estudar; moças mães-solteiras; rapazes pais-solteiros; rapazes e moças que nunca migraram, tampouco saíram do pequeno bairro rural; jovens que participam de grupo de teatro; que são religiosos, católicos ou protestantes. Enfim, grupos de jovens que se diferenciam entre si mediante as experiências que vão se somando e contribuindo para a formação de suas identidades ${ }^{4}$ e que, por sua vez, correspondem fortemente ao grupo familiar de origem. Portanto, conforme diz Machado Pais (1993):

(...) a juventude começa por ser uma categoria socialmente manipulada e manipulável e, como refere Bourdieu, o facto de se falar dos jovens como 
uma 'unidade social', um grupo dotado de 'interesses comuns' e de se referirem esses interesses a uma faixa de idade constitui, já de si, uma evidente manipulação. (p. 24)

Assim, o autor chama a atenção para o fato de que é preciso, antes de mais nada, compreendermos a juventude para além de suas "possíveis ou relativas similaridades"; compreendê-la nas "diferenças sociais". Com isto, está considerando que os grupos juvenis são diferentes e podem se identificar como tal. As observaçôes realizadas em Chapada do Norte também apontaram para tal fato, além de demonstrarem a importância da família na vida dos jovens. Pois é neste laço afetivo-familiar tão estreito que os jovens vão mediando e formando suas personalidades, construindo suas identidades e suas maneiras de se verem e de se auto-representarem.

Tal como observou Carneiro (1998, p. 101), que pesquisou jovens rurais numa "colônia italiana" na região de Nova Pádua (Caxias do Sul, RS) “(...) o compromisso moral com a família é ainda muito forte, proporcional ao reconhecimento pela 'ajuda' familiar, o que cria uma situação de dívida jamais quitada". No caso de Chapada do Norte, atitudes extremas de distanciamento, por parte dos jovens, na relação familiar, também podem ser consideradas: uma vez migrantes, para romperem com os laços e conseguindo constituir família, nunca mais voltam ou, quando muito, mandam apenas notícias.

Mas há também os jovens que ficam no caminho, indo e vindo. Ficam um tempo fora, depois voltam porque não agüentam as saudades, ou não conseguem se adaptar. Sendo que este tempo fora tanto pode ser por motivos de trabalho e estudo como, apenas, trabalho. Alguns acabam tendo que morar em casa de parentes, irmãos (na maioria já casados) ou padrinhos, que moram em centros urbanos maiores (neste caso, não se trata da migração sazonal para os centros da agroindústria).

Portanto, vê-se que a construção das identidades dos jovens desse rural brasileiro (Chapada do Norte) também vai acontecendo num emaranhado de ambigüidades e conflitos, pois ao mesmo tempo em que estes se vêem apegados à família, por sua vez, à "tradição" que lhes confere o sentido de reciprocidade, religiosidade, também pensam na possibilidade de ganharem dinheiro e terem uma vida melhor.

É importante observarmos que dentre as investigações que têm sido realizadas sobre a juventude/juventudes, as pesquisas de Marília Spósito (1999) têm demonstrado que, 
(...) ocorrem formas diversas de ingresso no mundo adulto, desde aquelas marcadas pela antecipação de algumas práticas (sexualidade e trabalho para alguns grupos de jovens) como a desconexão entre elas (...) a (...) emergência de necessidades apontada pelos segmentos juvenis não só voltadas para projetos futuros, mas cada vez mais marcadas pela especificidade do momento presente. (p. 8)

Neste sentido, há uma quebra da "referência temporal" para o ingresso na vida adulta que varia conforme a "origem social, étnica, religiosa ou regional e as relações de gênero (...)" (idem, ibid.), de tal maneira que, para as populações mais empobrecidas, há uma tendência, cada vez maior, à antecipação da vida adulta, também fortemente observada no meio rural de Chapada do Norte.

A pesquisa demonstrou que no referido município do Vale do Jequitinhonha, ocorre uma combinação da "antecipação da sexualidade, trabalho e emergência de necessidades" que demarcam o "momento presente". Os jovens deixam a escola, pois, muitas vezes, se vêem num processo de sucessivas repetências, seja porque têm de migrar para completar a renda familiar; abandoná-la, temporariamente, para ajudar os pais no plantio quando chega o período de chuvas; ou porque a escola que têm não lhes oferece perspectivas de futuro profissional, principalmente no momento de entrada no mercado de trabalho; seja pelo acontecimento de uma gravidez precoce. $\mathrm{O}$ que significa dizer que o projeto individual de futuro vai ficando cada vez mais distante.

Então, os jovens de Chapada do Norte, diferenciados como grupo e como membros de famílias distintas, tanto na área rural quanto na área urbana, constróem a identidade pela frustração? Uma resposta afirmativa para esta questão deve ser relativizada, pois ao que tudo indica, o sentimento de frustração está diretamente relacionado com a falta de trabalho, de possibilidades para uma vida profissional digna, que está associada ao sentimento de "descrença" frente ao ensino que tiveram. Sentimento este que coloca um desafio para os jovens: o de tentar superá-lo. Nessas tentativas, porém, acabam enredados pela necessidade e pela falta de recursos financeiros.

Sendo assim, o quê têm de mais imediato para minimizarem tais problemas são os canaviais das usinas de cana-de-açúcar de Ribeirão Preto, Araraquara, no interior do estado de São Paulo, ou nas fazendas de café no sul do estado de Minas Gerais. Também, os empregos de auxiliar de pedreiro e mecânico, entre outros, em capitais como São Paulo e Belo Horizonte. Ou, ainda, no caso das moças, 
trabalhar nas chamadas "casas de família" nos grandes centros, como empregadas domésticas ou babás.

Tais constatações, por outro lado, levam-nos a considerar que para muitos jovens é como viver numa espécie de "sina". De tal maneira que, muito provavelmente, à medida que a sociedade avança e guardada as devidas proporçôes, eles estão reproduzindo as mesmas dificuldades que seus pais tiveram para se manterem na escola, pois muitos destes são analfabetos ou semi-analfabetos.

Dados estatísticos do IBGE (Instituto Brasileiro de Geografia e Estatística, 1996), nos quais me apoiei no período da pesquisa (19971999), já demonstravam altos índices de evasão escolar no município investigado. Entre os que freqüentavam e os que não freqüentavam escola, os dados começavam a desequilibrar na faixa dos 15 a 19 anos 20 a 29 anos com os que não freqüentavam. Por exemplo, até a ocasião das investigações para elaboração da dissertação de mestrado, constava que entre moças e rapazes da área rural, da respectiva faixa etária, 479 jovens freqüentavam escola e 2.413 jovens não freqüentavam, num total de 2.892 jovens em idade escolar, sendo que as moças eram as que permaneciam por mais tempo na escola quando comparadas aos rapazes. Muito provavelmente pelo fato de não ingressarem no processo de migração sazonal tão rapidamente como os rapazes. Porém, permanecendo em casa, as moças têm de se equilibrar entre os estudos e os trabalhos domésticos ou trabalhos domésticos remunerados, em casas de famílias na área urbana do município. Em contrapartida, foi observado que os rapazes têm uma predisposição muito maior para abandonar os estudos em função do trabalho.

Muito embora os jovens entrevistados (que freqüentavam escola), em seus depoimentos, tenham dito que a escola que têm é boa, muito boa, não suavizam o fato de que, se há um número representativo de evadidos escolares, para não dizer, superior aos que freqüentavam a escola, ainda temos uma pergunta para ser respondida: por que desistem os demais jovens? Será que o problema está só na escola?

A Secretaria de Estado da Educação de Minas Gerais, preocupada com os altos índices de analfabetismo e evasão escolar dessa região do Vale do Jequitinhonha, desenvolveu projetos que visavam reintegrar estes estudantes à escola. O Projeto "Acertando o Passo" destinou-se àqueles que pararam ou estavam atrasados nas séries dos Ciclos do Ensino Fundamental. ${ }^{5} \mathrm{Ou}$ seja, o referido projeto tinha 
como principal objetivo fazer com que alunos "atrasados" e desistentes concluíssem a etapa do ensino fundamental de $5^{\mathrm{a}}$ a $8^{\mathrm{a}}$ série.

Procurei professores, diretor(a) e jovens estudantes e ouvi seus depoimentos acerca do projeto. Nas falas de professores e diretor(a) pude constatar as insatisfações com o mesmo, sobretudo, devido às dificuldades em adequarem o projeto à realidade dos alunos. Tais como: os jovens não conseguirem acompanhar regularmente os períodos letivos devido a tantos outros problemas, dentre eles os ocasionados pela seca, no caso dos jovens da zona rural que partem para a migração sazonal; desistências e afastamentos escolares para trabalhar na lavoura (doméstica) que vão, por sua vez, gerando o "atraso", a não assimilação e continuidade dos conteúdos; o cansaço devido ao trabalho em outras atividades; a baixa auto-estima, a vergonha por serem repetentes, o que, por sua vez, vai gerando o descompasso entre a idade e o ano escolar. Enfim, questões centrais para os jovens que não foram consideradas pelo projeto.

O resumo ou enxugamento das matérias, consequentemente dos anos letivos em semestres, é outro fator que, num primeiro momento, é anunciado como algo que irá "resolver" o problema do tempo e da conclusão das séries para os que estavam atrasados. Porém, grosso modo, os alunos levam um empurrão para que se enquadrem nas fileiras dos futuros "alfabetizados", pelo menos no ensino fundamental (no caso deste projeto). Ou seja, os alunos cursam $5^{a}$ e $6^{a}$ séries (em um ano) e depois $7^{\mathrm{a}}$ e $8^{\mathrm{a}}$ séries (em mais um ano), concluindo cada série em apenas 06(seis) meses. Conforme o depoimento de uma jovem entrevistada:

(...) Eu tenho que dar conta de aprender as matérias em 6 meses, a $8^{a}$ série mesmo, eu já saí, agora, em agosto eu terminei e estou fazendo o $1^{\circ}$ ano. Posso falar a verdade? Eu vou lá uma vez na escola. Algumas coisas eu aprendo, só que é o tipo de coisa passa aluno sem saber. Eu mesma fiz prova de matemática, mas a professora falou: 'por seu comportamento, por isso e por aquilo, você já está passada', eu já estou no $1^{\circ}$ ano. Muitas pessoas também lá foi do mesmo jeito. (20 anos, $1^{\circ}$ ano do ensino médio, empregada, moradora na cidade)

Entretanto, quando perguntei para a jovem entrevistada se ela achava que o conteúdo dado era muito para um tempo relativamente curto, ela colocou-me outra questão bastante importante: o conteúdo dado num tempo mais reduzido também demonstrava que a matéria estava sendo diminuída, pois como em suas pala- 
vras: “(...) aí eu saio da escola, eu me formei, chego no vestibular, eu nunca vi isso".

Numa conversa que tive com uma professora de Matemática na área rural de Chapada do Norte, pude verificar que, também, para ela reduzir o tempo letivo significava ter que diminuir o conteúdo da matéria. Assim me falou a professora:

(...) É um projeto que ele funciona assim, prá quem é responsável. Mas é um projeto onde você condensa... eu mesma tive que condensar (...). $\mathrm{O}$ programa de Matemática que veio para mim de Diamantina, eu não usei ele, não. Realmente foi um programa que estava... não era a realidade do pessoal daqui de Chapada. Eu fiz umas mudanças e tive de condensar o programa inteiro! O que você vê em um ano, está na sala fazendo atividades, é diferente do que você vê em 100 dias letivos. 100 dias letivos não dão para o aluno, principalmente de Matemática que é uma matéria que requer raciocínio... você tem que fazer muito exercício e isso em 100 dias era muito corrido. (...) Vão alunos cansados que trabalham o dia todo, é... na prefeitura, trabalharam, assim, serviços gerais. Vão mais alunos que trabalharam em marcenaria; trabalham na zona rural com enxada mesmo; mães de família que têm 6, 7 filhos em casa, largam os filhos vão para escola. Chegam na sala uns cochilam, outros... (...) e é muito difícil, muito difícil trabalhar mesmo. Não tem rendimento. (26 anos, professora de Matemática na zona rural, moradora na cidade).

Desse modo, observei que a experiência de alguns professores e alunos com o referido projeto teve, pelo menos, dois marcos importantes: o primeiro, o da expectativa - por parte dos alunos - de concluírem os estudos ou adiantarem-se à etapa seguinte (do ensino médio) e - por parte dos professores -, de que os alunos conseguissem assimilar e se motivassem nos estudos; o segundo, o da frustração - tanto por parte dos professores quanto dos alunos - devido à dificuldade de acompanhamento e assimilação do conteúdo dado e à falta de motivação para estudar o que ficou para trás.

Por outro lado, permanecem as seguintes perguntas: por que projetos como o Acertando o Passo (e outros), que tiveram ou têm como intento a diminuição do analfabetismo e evasão escolar, fracassam em regióes como a do Vale do Jequitinhonha, por exemplo? Qual ou quais as premissas que o governo se pauta na hora da elaboração desses tipos de projetos?

As iniciativas governamentais, por meio de projetos educacionais que visem a minimizar problemas tão arraigados como o analfabetismo e a evasão escolar, acabam muito mais por corroborar a 
falta de perspectivas destes jovens. Sobretudo, porque oferecem uma aprendizagem escolar que não lhes possibilita concorrer com igualdade, tanto nos estudos (ensino universitário, por exemplo) como no campo profissional.

Todavia, quando não se consegue romper com os modelos ${ }^{6}$ estabelecidos para a educação formal; quando não se quer enfrentar o fato de que também é preciso aprender a se transformar, não se estaria nivelando por baixo o ensino a ser oferecido para esta população, considerando, talvez que eles querem apenas um diploma? Alguém poderá até indagar: e não é? Responder afirmativamente a esta pergunta é o que vem fazendo ou acreditando o próprio sistema de educação, que se pauta teoricamente pela igualdade, porém trata desigualmente os indivíduos, quando não os considera nas suas diferenças culturais, sejam elas regionais ou locais.

Portanto, inserir projetos que não privilegiem o contexto da região, as dificuldades e problemas por que passam os alunos, não poderá assegurar a cidadania para estes por meio do estudo, pois serão apenas números positivos que amenizam as estatísticas do analfabetismo e evasão escolar, mas não devolverão aos jovens o sentimento de que pertencem a uma sociedade, com iguais direitos de obterem um ensino "inteiro e não pela metade".

Em outras palavras, projetos no âmbito do ensino formal que não partam de dentro para fora, que não avaliem a realidade dos alunos aos quais se destinam, poucas chances têm de atingir seus objetivos com sucesso. Por outro lado, projetos assistenciais que trazem no bojo aspectos educativos não-formais podem sinalizar uma saída para suprir deficiências da aprendizagem formal.

Um caso observado foi o projeto da ACHANTI, em convênio com o Fundo Cristão para Crianças. Este projeto é voltado para a assistência às famílias rurais, de tal modo que estas possam permanecer na roça, diminuindo também a desnutrição infantil e problemas como falta de creches para crianças de mães que trabalham; e, junto aos jovens, com programas que lhes ensinem algum trabalho técnico e orientem sobre gravidez e anticoncepção.

Para que o(a) leitor(a) possa compreender melhor este programa de assistência é importante conhecer a origem da organização filantrópica denominada "Fundo Cristão para Crianças". A referida organização é inspirada na Christian Children's Fund, uma entidade que surgiu por iniciativa de um casal americano, para dar respostas 
às cartas de missionários de origem cristã que solicitavam dinheiro e ajuda para os órfãos de guerra. Em Setembro de 1938, fundou-se a China' Children Fund (Fundo para as Crianças da China), utilizando o método de apadrinhamento individual da criança para arrecadação de fundos. Na década de 1960 , porém, o objetivo modificase: de órfãos de guerra passam aos carentes dentro de suas próprias famílias. Em 1964, portanto, o programa expande-se para o Terceiro Mundo. No ano de 1971 foi instalado o primeiro escritório regional no Brasil, na cidade de Belo Horizonte (MG). O segundo escritório foi em Fortaleza (Ceará). ${ }^{7}$

Os critérios para que uma criança seja cadastrada no Programa de Apadrinhamento do Fundo Cristão para Crianças na ACHANTI são os seguintes: "a gente faz pelo nível socioeconômico. A gente tem uns critérios que é ser cristão, renda per capta é $\mathrm{R} \$ 50,00$ que é a criança até 12 anos, não é isso? Até 12 anos e tem uns critérios, né? Tem que ser em zona rural. São esses critérios, né... a gente faz um levantamento, pega as crianças mais carentes e para inscrever tem que ser até doze anos. Agora, ela pode ficar no programa até dezoito, né (...). E quando o padrinho quer continuar, mesmo que faz dezoito, se o padrinho quiser continuar, aí continua... aí no caso é o padrinho, né?", explicou-me a coordenadora (na época da pesquisa) da referida associação.

A quantia que cada padrinho enviava mensalmente para a criança ou jovem apadrinhado (pode ter casos em que há mais de um apadrinhado por família), na época, era de $\mathrm{R} \$ 26,00$ (vinte e seis reais). Desse valor, são recolhidos $\mathrm{R} \$ 9$ (nove reais) para o Fundo Cristão, que, conforme informou-me um funcionário da associação, destinam-se à manutenção, gastos administrativos: compra de equipamentos, mandar cartilha, ferramentas. Enfim, o que irá para a ACHANTI (Projeto) são $\mathrm{R} \$ 17$ (dezessete reais). Ou seja, existe a doação de uma quantia fixa que é transformada em programa de assistência às famílias em cada comunidade rural, através do Programa de Apadrinhamentos, que é o que acaba por gerar maior suporte financeiro para a associação.

Os jovens apadrinhados desenvolvem trabalhos sobre agricultura, com orientação de funcionários da associação, sobre plantio e formação de apicultores, bem como a respeito de prevenção da gravidez e exames preventivos. Não obstante, a pesquisa demonstrou que, mesmo com as doações que os padrinhos enviam mensalmente à crianças e jovens e, também, presentes (quase sempre em forma 
de cheques extra-doações), não são suficientes para abrandar ou melhorar as condiçôes de vida das famílias rurais. Não resolvendo, portanto, o problema das migrações, sobretudo em períodos de seca.

O problema é que os apadrinhados, sejam eles jovens ou crianças, se não se encontram em seus locais de morada e na escola, não podem continuar no programa de apadrinhamento, devem ser desligados. Se estão em suas terras, mas abandonam a escola (mesmo que temporariamente) para trabalharem na lavoura, também correm o risco de serem desligados do programa. Então, o que devem fazer? Famílias inteiras devem permanecer dependentes de doações para um, dois filhos apenas, enquanto que na maioria das vezes são cinco, seis, sete ou mais filhos? Isto não seria um modo de aprisionálos ainda mais na condição de dependentes e miseráveis? Ou seja, será que "o pouco com Deus ainda não é pouco"?

Por outro lado, como condicionar os jovens à escola, bem como ao campo de origem, de tal maneira que se vejam "vigiados" ou "obrigados" a neles permanecerem para que continuem sendo apadrinhados, quando a escola rural que têm concorre para que a deixem o mais cedo possível? Como diz Brandão (1990, p. 175), a meta da escola rural é "sempre" produzir algum resultado, mesmo que precariamente, de geração a geração. Por isso, num nível mais amplo, ela mais contribui para alimentar anseios do que saber, impulsionando o "jovem trabalhador rural para abandonar o campo por um emprego (ou subemprego) na cidade".

Dito com outras palavras, mesmo um programa de assistência como o de Apadrinhamento do Fundo Cristão para Crianças, em regiōes como a do Vale do Jequitinhonha, acaba criando outros conflitos porque, ao que tudo indica, os critérios dessa organização filantrópica acabam por não dar conta do cotidiano e problemas específicos dos moradores de cada localidade. Ou seja, trata-se de critérios pouco flexíveis, pois seguem um modelo prescrito para populações carentes. Estas, por sua vez, é que devem, sim, se enquadrar no programa.

Não obstante, mesmo conflituosamente, o Programa de Apadrinhamento, aos apadrinhados e às famílias, acaba desempenhando também o seu papel educativo. Porém, observei que os jovens rurais, diante principalmente dos jovens da área urbana de Chapada do Norte, eram vistos de maneira enviesada, pois além de serem da roça ainda carregavam o "rótulo" de carentes, pobres. 
Entretanto, acabei por constatar que há nesse município jovens - rapazes e moças - realizando diferentes movimentos, diferentes trajetórias entre diferentes sujeitos. Por isso, é possível realizar o exercício de caracterizá-los em três grupos macros: A) estudantes; B) nãoestudantes e C) estudantes temporários (ou sazonais). Depois, é possível fazer uma associação direta com o núcleo familiar de origem desses jovens. Sendo assim, nos três grupos macros encontrei jovens que são: filhos de pequenos agricultores e migrantes sazonais; filhos de encarregados de turma (ou "gato") para os trabalhos no corte da cana-de-açúcar ou colheita de café; filhos de latifundiários (alguns falidos); filhos de pequenos comerciantes; filhos de aposentados (pelo município ou governo estadual) (Silva, 2000).

Por sua vez, estes jovens podem ser identificados por subgrupos: A1) estudantes (sustentados/família ou apadrinhamento); estudantes-trabalhadores (com remuneração ou sem remuneração); estudantes-trabalhadores-agentes culturais (grupo de teatro); estudantes-trabalhadores-agentes religiosos (grupo de jovens católico ou protestante); B1) não-estudantes-migrantes sazonais; não-estudantes-trabalhadores-pais (solteiros ou casados); C1) estudantestemporários-migrantes (cana-de-açúcar ou café); estudantes-temporários-pais (solteiros ou casados) (Silva, op. cit.).

No cotidiano com os demais moradores do município, nas conversas, nos modos de se portarem em ambientes de festas, bailes ou mesmo quando andavam pelas ruas, os jovens, associados a um determinado grupo e subgrupo, mostravam-se mais ou menos propensos a estabelecer relaçóes de amizade com outros jovens de um outro grupo e subgrupo.

Todavia, as resistências ou intolerâncias e desconfianças por parte dos jovens, tanto da área urbana quanto das áreas rurais, eram sentimentos que faziam a diferença; assim como as vestimentas, a escolha de determinados acessórios, os comportamentos eram determinantes para a concretização das aproximações ou não. Não esquecendo, também, do núcleo familiar que é importante para que um rapaz ou uma moça aproxime-se de outro(a) jovem; sobretudo, porque tal observação é feita primeiramente pelos adultos, os pais, os avós informando, portanto, com quem ou com que tipo de jovem se deve ou não fazer amizade. Também observei que não estão descartadas as transgressões por parte de alguns jovens, mais os que estão na área urbana do que os que permanecem nas áreas rurais. 
Por exemplo, os que são estudantes-trabalhadores ou mesmo os estudantes (sustentados/família ou apadrinhamento) poderiam estar mais integrados, desde que, em muitos casos, fossem com outros jovens da área urbana. Porém, se um ou outro jovem fosse da área rural já havia manifestações de resistência para a consolidação de uma relação de amizade. Em alguns depoimentos, jovens da área rural afirmaram desconfiar dos jovens da área urbana, pois diziam que ser jovem em Chapada "não é muito bom, pois não temos uma juventude unida" (jovem do sexo masculino, 18 anos, $2^{\circ}$ ano do ensino médio, morador da área rural temporariamente na área urbana); "não é totalmente legal, pois tem um pessoal complicado" (sexo masculino, 18 anos, $1^{\circ}$ ano do ensino médio, morador da área rural, temporariamente na área urbana). Outro depoimento, desta vez de um rapaz da área urbana sobre como vê o jovem da área rural, é interessante para percebermos quão enviesados são os olhares de uns sobre os outros:

Eu tenho amizade com muita gente da roça... muito pessoal da roça. $\mathrm{O}$ pessoal aqui tem aquela certa distância, não por mim, mas por muita gente, tem... talvez até por mim, também. O pessoal da roça fica mais, assim, na deles; o pessoal da cidade, não entrosa muito com o pessoal da roça (...). Agora, o pessoal da roça daqui de Chapada, eles são mais assim... parece que são um pessoal mais agressivo; tudo deles é na base da ignorância [risos] e isto distancia eles, um pouco, do pessoal da cidade (...). (21 anos, ensino secundário completo, morador da área urbana, estudos preparatórios para ingressar na faculdade, fora do município)

Com os depoimentos como os dos jovens acima citados mais as observações de campo, foi possível perceber que há uma certa tensão entre os jovens, sobretudo quando estes não se vêem identificados com outros jovens ou não percebem, através de acessórios, roupas de marcas, os símbolos de consumo que sinalizam para as aproximaçōes ou não. Assim, faz diferença, entre os jovens desse município, ser um jovem estudante da área urbana (nascido e criado) e ser um estudante da área rural, assim como ser estudante na área urbana vindo da área rural. Por isso, a idéia ou hipótese que venho defendendo diz respeito à diversidade dos jovens do rural, seja entre os de Chapada do Norte, seja entre os de outros municípios da região do Vale do Jequitinhonha.

Portanto, não falo de uma cultura juvenil rural, mas de culturas de jovens com suas variadas formas de ser, sentir, agir e pensar. Que culturas são essas, então, se se pensar que o contexto investiga- 
do se traduz por uma cultura que se expressa através de uma tradição, ${ }^{8}$ que demarca as relações sociais deste município? Culturas dos jovens em oposição a uma cultura adulta vigente?

As discussões em torno do conceito de cultura juvenil colocam em questão os limites entre juventude e velhice, o jovem e o adulto, ou onde começa um e o outro. Sendo assim, trata-se de discutir não o caráter de antagonismo dessas culturas, adulta e juvenil, mas, sim, a sua complementaridade enquanto espelhos reflexos uma da outra ou uma para a outra ou, ainda, sua oposição complementar.

Neste sentido, Bourdieu diz que "(...) as relaçôes entre a idade social e a idade biológica são muito complexas", pois chama atenção para as "leis específicas" de cada grupo e o determinismo destes, conforme os seus interesses específicos; ou seja, “(...) mostra que a idade é um dado biológico socialmente manipulado e manipulável; (...)" (1983, p. 113). Portanto, considerar a juventude como uma unidade social configura-se numa total manipulação.

Desse modo, não vendo os jovens de Chapada do Norte como "unidade", eles também não estão isolados do processo social, portanto de socialização, que lhes remete a valores, costumes com os quais aprenderão a conviver. Pois é na convivência cotidiana que os jovens vão reelaborando valores, normas que lhes são passadas pelo grupo familiar-social.

Nas negociações entre jovens e adultos, dá-se um "processo de socialização" e "juvenização". Na passagem para a vida adulta, o "processo de socialização" tem papel importante, pois, segundo Machado Pais (1993), este é um processo de "influências sociais, orientado para a integração dos jovens num dado sistema de relaçóes e valores sociais, (...)"; em contrapartida, este será alvo das "influências dos jovens sobre a sociedade, embora também seja possível falar de uma socialização da juvenização" (p. 60).

Não obstante, é importante fazer ressalvas quanto à intensidade deste processo de "juvenização" numa sociedade como a de Chapada do Norte, na qual os jovens estão inseridos num contexto em que coexistem o tradicional e o moderno. Sendo que ao primeiro reporta-se uma boa parcela da população adulta, sobretudo no que diz respeito às condutas e comportamentos desejados socialmente. Todavia, os jovens transitam entre o rural e o urbano, comunicando suas releituras desses dois universos, o que culmina num ideal de vida "rurbano". 
(...) Abrir novas alternativas de trabalho no campo é um projeto que surge em função da perspectiva de estreitamento dos laços com a cidade, favorecido pelas facilidades dos meios de comunicação. É nesse contexto que os ideais da juventude rural apontam para uma síntese, que definimos como projeto de vida rurbano. (Carneiro, 1998, p. 113)

Entretanto, este ideal "rurbano" também é relativizado para o caso de Chapada do Norte, afinal, não se trata de uma realidade com novas perspectivas e alternativas de trabalho para os jovens do rural, mediatizadas por experiências com o urbano, tal como observou Carneiro (op. cit.) entre os jovens de um município do Rio Grande do Sul e do Rio de Janeiro; mas, sim, de uma realidade em que os jovens, ao transitarem entre o rural e o urbano, vão assimilando, portanto, valores de outras sociedades que serão reinterpretados a partir dos modelos tradicionais da sua sociedade local. O que significa dizer que poderão influenciar numa "reconstrução cultural", lenta e gradual, ou poderão apenas assimilar bens de consumo e conviverem no sistema dos valores do lugar, o sistema dos mais velhos, pois tudo vai depender da "criação"; ou seja, do modo como foram educados.

Nesse sentido, segundo Carneiro (1998), se observarmos pela "perspectiva das sociedades com forte referência à 'tradição', (...) esse processo supõe também, como resultado da relação de alteridade, a reafirmação de valores e modos de vida locais - sobretudo os que são elaborados no interior do universo familiar”. Decorrente disso, acontece da sociedade local se reafirmar "a partir de definições e redefinições das identidades" que são mantidas, porém, não mais nos moldes de padrões culturais homogêneos, mas sim dentro da diversidade desses padrões, e ainda mais, diz a pesquisadora, "na maneira específica de combinar práticas e valores originários de universos culturais distintos, o que identificamos como rurbanização" (p. 115).

Finalizando, é importante assinalar que ainda existe a tensão entre escola e família (alguns tipos de família) na educação dos jovens e crianças de Chapada do Norte. Isso apareceu como uma espécie de "disputa" não revelada, mas que pôde ser caracterizada, muitas vezes, pelo desinteresse por parte dos pais na continuidade dos estudos dos filhos. Sendo que, em determinadas áreas do rural, esteve mais presente entre os pais com pouca escolaridade o seguinte raciocínio: "por que que com meu filho vai ser diferente..."; ou entre os filhos (jovens) que abandonaram a escola: "se meu pai ou minha mãe chegaram até aqui sem estudo prá que qu'eu vou me preo- 
cupar?”. Ou entre alguns jovens que nunca migraram, mas que também não conseguiram avançar nos estudos, onde percebi que isso alimentava o sentimento mútuo de vergonha entre pais e filhos. Como no dizer de uma mãe: "meu filho não dá para os estudos". Houve, porém, professores que disseram-me que estes modos de pensar, por parte de alguns pais, já estão mudando.

Portanto, seria oportuno e urgente investigações mais aprofundadas sobre o desempenho de projetos como o Acertando o Passo, por exemplo, em diferentes regiões de um mesmo estado, de tal sorte que se refletisse sobre o "sucesso" e o "insucesso" em determinadas localidades, com vistas a uma análise dos "alfabetizados" que estão sendo gerados no Brasil e os alfabetizados que não estão; assim como pensar projetos como este, vinculando escola e família, uma vez que, em regiôes como a que foi estudada ou que sejam pouco desenvolvidas (sócio-economicamente), a educação informal tem um grande peso para o encaminhamento dos estudos.

Para concluir, constatei que os jovens rurais do município de Chapada do Norte, sobretudo aqueles cujas trajetórias de vida se dão entre o rural e o urbano, estão vivendo experiências de elaborar e reelaborar práticas, valores dos dois universos culturais, de tal maneira que vê-se existir diferentes grupos e subgrupos de jovens: A) Estudantes; B) Não-estudantes e C) Estudantes temporários (ou sazonais); A1) estudantes (sustentados/família ou apadrinhamento); estudantes-trabalhadores (com remuneração ou sem remuneração); estudantes-trabalhadores-agentes culturais (grupo de teatro); estudantes-trabalhadores-agentes religiosos (grupo de jovens católico ou protestante). B1) não-estudantes-migrantes sazonais; não-estudantestrabalhadores-pais (solteiros ou casados). C1) estudantes-temporários-migrantes (cana-de-açúcar ou café); estudantes-temporários-pais (solteiros ou casados) (Silva, 2000).

Tal constatação, no mínimo, reforça, cada vez mais a afirmativa da diversidade cultural desses jovens. Porém, cabe ainda perguntar: qual ou quais as conseqüências dessa constatação para esse universo rural escolar? Este é mais um dos desafios a serem enfrentados.

\section{Notas}

1. Dissertação intitulada "Eles não têm nada na cabeça...": jovens do sertão mineiro entre a tradição e a mudança. Faculdade de Educação da UNICAMP, 2000. Este artigo é uma adaptação de um capítulo da referida dissertação, orientada pela Profa Dra Neusa Maria M. de Gusmão. 
2. A inspiração é o trabalho do pesquisador português José Machado Pais, Culturas Juvenis (Lisboa: Imprensa Nacional Casa da Moeda, 1993), que investigou diferentes grupos de jovens urbanos em Lisboa.

3. Cf. Maria Isaura Pereira de Queiróz (1973, p. 53): “a família do sitiante se define como conjugal do ponto de vista econômico, porém se define como parentela, quando tomamos a perspectiva das relações sociais". In: Galizoni, F.M. A terra construida: família, trabalho, ambiente e migraçóes no alto Jequitinhonha, Minas Gerais. Dissertação de Mestrado. Departamento de Antropologia Social da Faculdade de Filosofia, Letras e Ciências Humanas da Universidade de São Paulo (FflCh/Usp), 2000, p. 4748 .

4. Para pensar sobre identidade parto da definição de Roberto Cardoso de Oliveira (1976, p. 5) de "identidade contrastiva", que busca compreender o "processo de identificação étnica" que, segundo o autor, "implica a afirmação do nós diante dos outros". Portanto, "uma identidade que surge por oposição". Pensando os jovens de Chapada do Norte, por este prisma da construção de identidades, ("nós", os jovens), esta se daria por oposição e complementação - aos adultos (os "outros"), uma vez que a família, para estes jovens, é um referencial muito importante.

5. Por coincidência, no mesmo ano em que a dissertação de mestrado que discute este projeto foi defendida (2000), foi anunciado que o Acertando o Passo seria finalizado.

6. Conforme Italo Calvino: “(...) O modelo é por definição aquele em que não há nada a modificar, aquele que funciona com perfeição; ao passo que a realidade, vemos bem que ela não funciona e que se esfrangalha por todos os lados; portanto, resta apenas obrigá-la a adquirir a forma do modelo, por bem ou por mal." Modelos dos modelos, in: Palomar, São Paulo: Companhia das Letras, 1994, p. 98.

7. Conforme o Manual de Comunicação Criança-Padrinho. In: Fundo Cristão para Crianças - Brasil.

8. A festa de Nossa Senhora do Rosário (padroeira de negros e pobres) pode ser vista como a expressão pública desse contexto de tradição. Festa que acontece no município de Chapada do Norte a mais de 150 (cento e cinqüenta) anos, quase sempre no segundo domingo do mês de outubro. Os festejos que acontecem durante vários dias são mantidos e preparados, sobretudo, pelos membros da Irmandade de Nossa Senhora do Rosário. Sobre esta festa ver: Liliana de Mendonça Porto, $A$ reapropriação da tradição a partir do presente: um estudo sobre a festa de Nossa Senhora do Rosário de Chapada do Norte - MG. Dissertação de Mestrado, Departamento de Antropologia da Universidade de Brasília (UnB) 1997.

\section{Referências Bibliográficas}

BOURDIEU, P. A “juventude” é apenas uma palavra. In: Bourdieu, P. Questôes de sociologia. Rio de Janeiro: Marco Zero, 1983.

BRANDÃO, C.R. Cultura camponesa e escola rural. In: BRANDĀo, C.R. $O$ trabalho de saber: cultura camponesa e escola rural. São Paulo: FTD, 1990.

\section{CALVINO, I. O modelo dos modelos: Palomar. São Paulo: Companhia das Letras, 1994.}


CARNEIRO, M.J. O ideal rurbano: campo e cidade no imaginário de jovens rurais. In: Silva, F.C.T.; SAnTOS, R.; Costa, L.F.C. (Org.). Mundo rural e politica: ensaios interdisciplinares. Rio de Janeiro: Campus, 1998.

CÉSAR, M.R.A. A invenção da "adolescência" no discurso psicopedagógico. 1998. 133f. Dissertação (Mestrado em Educação) - Faculdade de Educação, Universidade Estadual de Campinas, Campinas.

GALIZONI, F.M. A terra construida: família, trabalho, ambiente e migrações no alto Jequitinhonha, Minas Gerais. 2000. 92f. Dissertação (Mestrado) - Faculdade de Filosofia, Letras e Ciências Humanas, Universidade de São Paulo, São Paulo.

OLIVEIRA, R.C. Identidade e identificação. In: OliveIRA, R.C. Identidade, etnia e estrutura social. São Paulo: Pioneira, 1976.

PAIS, J.M. Culturas juvenis. Lisboa: Imprensa Nacional-Casa da Moeda, 1993.

SPÓSITO, M.P. Estudos sobre juventude em educação. Revista Brasileira de Educação, Belo Horizonte, n. 5/6, 1997. Número especial.

SPÓSITO, M.P. Educação e juventude. Educação em Revista, Belo Horizonte, n. 29, p. 7-13, jun. 1999.

SILVA, V.A. "Eles não têm nada na cabeça...": jovens do sertão mineiro entre a tradição a mudança. 2000. 189p. Dissertação (Mestrado em Educação) - Faculdade de Educação, Universidade Estadual de Campinas, Campinas. 